\title{
Meat consumption and capitalist development: The meatification of food provision and practice in Vietnam
}

\author{
Arve Hansen \\ Centre for Development and the Environment \\ University of Oslo
}

arve.hansen@sum.uio.no

Postboks 1116 Blindern, 0317 OSLO

\begin{abstract}
The global consumption of meat and animal products has increased dramatically in recent decades, particularly due to rising consumption in so-called developing countries. This increase has popularly been explained as part of a "nutrition transition" driven by rising income, urbanisation and foreign culinary influences. From the supply side, the increase has been approached as part of a "livestock revolution", or alternatively as the outcome of capitalist agricultural processes. This paper argues, however, that these explanations have given insufficient attention to how and why consumption of meat changes. The paper analyses the case of Vietnam, where meat consumption has increased very rapidly since the initiation of market reforms in 1986. In understanding how meat consumption and development have coevolved, the paper argues that consumption should be approached at the intersection between systems of provision and everyday practices. With this backdrop - and partly combining, partly going beyond standard explanations - the paper locates four main contributing factors towards increasing meat consumption in Vietnam: (1) changes in systems of provision for meat, (2) the meat intensification of traditional meals and the import of meat-intensive eating practices from abroad, (3) the increasing prevalence of eating out; and (4) the positive social connotations attached to meat as a symbol of development and progress. The paper goes on to argue that the dramatic meatification of food provision and practice in Vietnam should be understood as the result of capitalist development processes and their associated economic and social changes, rather than the 'natural' and inevitable outcome of development.
\end{abstract}

Keywords: Vietnam, consumption, meatification, development, nutrition transition, livestock revolution 


\section{Introduction}

Over the last decades, global consumption of meat and animal products has increased dramatically. By 2013, total global meat supply reached 302 million tonnes, and global annual average meat consumption per capita hit $43 \mathrm{kgs}$, compared to $23 \mathrm{kgs}$ in 1961 (FAOSTAT) ${ }^{1}$, despite the global population more than doubling in that period. As FAO pointed out in the seminal report, Livestock's Long Shadow, until the early 1980s daily consumption of meat and dairy products was mainly an OECD privilege (Steinfeld et al. 2006). Then in the subsequent two decades, total global meat supply almost doubled from 133 million tonnes in 1980 to 239 million tonnes in 2002. In developing countries, total annual meat supply tripled (from 47 million tonnes to 137 million tonnes) while annual per capita meat consumption doubled (from $14 \mathrm{kgs}$ to $28 \mathrm{kgs}$ ) in the same period. (Steinfeld et al, 2006). The upwards spiralling trend has continued and is expected to persist over the coming decade (OECD/FAO 2016; Henchion et al., 2014).

From a food, nutrition and well-being perspective, some increase in meat consumption in developing countries can have very positive effects. However, meat production is a highly inefficient way to provide food to a growing population and current consumption levels and production processes have serious environmental consequences (Weis, 2013a; Neo and Emel, 2017). For example, livestock systems already emit up to 18 per cent of total greenhouse gases and use 25-32 per cent of global fresh water (Herrero et al., 2015). While it is certainly possible to make livestock processes more efficient and more environmentally friendly (e.g. Kristensen et al., 2014; Herrero et al., 2015), current trends in meat consumption are unsustainable, and a further global-scale increase in consumption is thus deeply problematic.

The increases in meat consumption in developing countries have popularly been seen as part of a "nutrition transition"2 (Popkin, 1993; Popkin et al., 2012) and a "livestock revolution" (Delgado et al., 1999; Delgado, 2003). While capturing important general trends, both ideas have been criticised for their simplicity and for being partly misleading. For example, as a global average, diets may not be changing as much as the "nutrition transition" suggests (PicaCiamarra and Otte 2011). As for the livestock revolution, it may more of a gradual evolution

\footnotetext{
${ }^{1}$ This massive growth has been driven mainly by consumption of poultry followed by pork (Henchion et al., 2014).

${ }^{2}$ In addition to meat and other animal source food, the nutrition transition refers to shifts towards more processed food, more sugar and more fats in a wide range of low- and middle-income countries (Popkin, 1993; Popkin et al., 2012)
} 
than a dramatic revolution (MacLachlan, 2015a; Pica-Ciamarra and Otte 2011). More importantly, as indeed acknowledged by Delgado (2003), these are not global as much as spatially uneven phenomena occurring in some regions and not in others. The livestock revolution, for example, has been very strong in parts of East and Southeast Asia, and nonexistent in most of Africa (Delgado, 2003) where only southern parts of the continent have seen any increase in per capita meat consumption (OECD/FAO 2016). Furthermore, Weis (2013ab) has criticised how these concepts make escalating meat consumption seem a natural and inevitable outcome of growing affluence, along the lines of old-school linear development thinking. Instead, he argues, we should be looking at how specific capitalist development trajectories, and most importantly industrial livestock production and associated industries, make what he terms the "meatification" of diets possible (Weis, 2013ab). A similar argument is made by Schneider (2017) based on the study of what she conceptualises as China's “industrial meat regime” (see also Schneider and Sharma, 2014; Sharma, 2014).

While the abovementioned scholarship has produced valuable insights on the political economy and economic geography of meat, a gap in both mainstream and critical accounts of surging meat consumption is consumption itself. More precisely, consumption trends are discussed, but the drivers of these trends are mostly assumed or generalised. In the literature on the nutrition transition and the livestock revolution, common explanations for changes in consumption are first and foremost increasing affluence, but also urbanisation and an associated convergence towards 'Western-style' diets (Kearney, 2010; Delgado, 2003; Popkin, 1999). In critical accounts, consumption is often mentioned, but it is production regimes that are studied. All of these are undoubtedly important factors, as will be discussed below. But they are also insufficient explanations. Decades of research on consumption has shown that although consumers are far from autonomous agents, they - or we - do possess considerable agency. Affluence makes more consumption of certain things possible, but not inevitable. As Weis (2013a) argues, there are few reasons to believe we as humans are programmed to eat as much meat as possible. Instead, as is discussed below, our eating habits, and consumption patterns in general, are shaped by both systems of provision and everyday practices. If the unsustainable global surge in meat consumption is to be confronted, we need to understand not only the forces and processes that have led to increased production but also the reasons why people eat more and more meat.

This paper analyses different developments contributing to escalating meat consumption in one rapidly growing economy, Vietnam, combining a focus on changes in production and 
provisioning with analysis of changes in everyday food practices. Through this study, the paper aims to contribute towards a more empirically grounded understanding of meat-intensive development trends. The paper makes three main contributions: First, in support of contributions by scholars such as Weis (2013ab) and Schneider (2017), it brings further evidence to the idea of meatification of food provision and practice as being the outcome of capitalist development strategies and processes, rather than inevitabilities based on human beings' insatiable hunger for meat. Second, it provides a contextualised analysis of rapidly increasing meat consumption in Vietnam. And third, it shows the importance of taking consumption seriously in order to understand how and why diets become meatified.

After an explanation of methodology, the paper starts with a discussion of the relationship between development and meat consumption based on existing literature, before zooming in on development and consumption in Vietnam. In the subsequent section, the paper analyses what I argue are the four main factors contributing to escalating meat consumption in Vietnam: increasing availability of meat, meat intensification of everyday food practices, increasing prevalence of eating out and the social significance of meat as a symbol of development and social status. Crucially, the paper goes on to argue, these are not 'natural' development trajectories, but the outcome of specific policies and of the spatial expansion of capitalism.

\section{Methodology}

The paper draws most directly on two periods of fieldwork in Hanoi in 2017, from March to May and in October. During this period I interviewed government officials, food and agriculture analysts, market vendors, restaurant owners, specialty food producers, farmers and representatives of abattoirs and villages engaged in livestock slaughter, as well as members of 20 middle-class households ${ }^{3}$, about food and meat consumption. Interviews varied in length, with the interviews with busy market vendors the shortest, sometimes as brief as a few minutes, and the household interviews the longest, usually around one hour. All interviews were semistructured. The household interviews were more in-depth than the others, and functioned as a form of semi-structured food conversation about everyday food purchases and preferences, cooking practices and eating practices, with particular emphasis on meat. Some were conducted

\footnotetext{
3 'Middle class' is here simply understood as neither belonging to the poorest nor richest segments of the population. While none of my informants were poor, some clearly belonged to the upper parts of the middle class.
} 
in Vietnamese with an assistant translator, and some in English. For the sake of clarity, some quotes in the paper have been slightly altered grammatically.

With an epistemological starting point valuing the importance of understanding local contexts and engaging in the everyday lived experiences of interviewees, interviews have been combined with an ethnographically oriented approach to food practices. From this perspective, while it is essential to talk to people in order to understand their worlds and lives (Kvale and Brinkmann, 2009), it is necessary to go beyond "sayings" and also consider "doings" in order to understand social practices (Halkier and Jensen, 2011). I thus also engaged directly in an extensive range of food practices, including shopping and eating at a wide variety of food spaces frequented by the city's middle classes. Through this engagement, as well as through the experiences of everyday life in Hanoi, I also had frequent informal food conversations with friends, colleagues, and acquaintances that have informed my understanding of the Vietnamese food scene. Crucially, and related to the latter point, the paper also draws on eight years of working in and on Vietnam in shorter and longer periods, where food has all along represented a central interest. My research is thus also informed by a large number of informal conversations about food, an estimated couple of thousand restaurant and street food meals all over Vietnam, as well as lunch and dinner meals at the homes of friends and acquaintances in several parts of the country.

The qualitative approach outlined above has been combined with secondary data from FAO, UN Comtrade and the General Statistics Office of Viet Nam. The following discussions thus draw on secondary data to outline macro trends of meat production and consumption as well as expert and policy-maker interviews to better comprehend Vietnamese food policies and priorities, interviews with producers and retailers to study systems of provision, and household interviews combined with a sort of 'eating ethnography' to approach and engage in everyday food practices.

\section{Meat and development}

There is a clear correlation between increasing meat consumption and increasing affluence, although only up to a point and with considerable variation (Grigg, 1995; Sans and Combris, $2015)^{4}$. Figure 1 shows the relationship between GDP and meat consumption (measured as food 
supply ${ }^{5}$ ). Statistical analyses support the inverted U-shaped relationship shown in the figure. The decrease at higher income levels is sometimes referred to as a possible "second nutrition transition" (Mathijs, 2015; Vranken et al., 2014).

Figure 1 Meat consumption and affluence, 2013

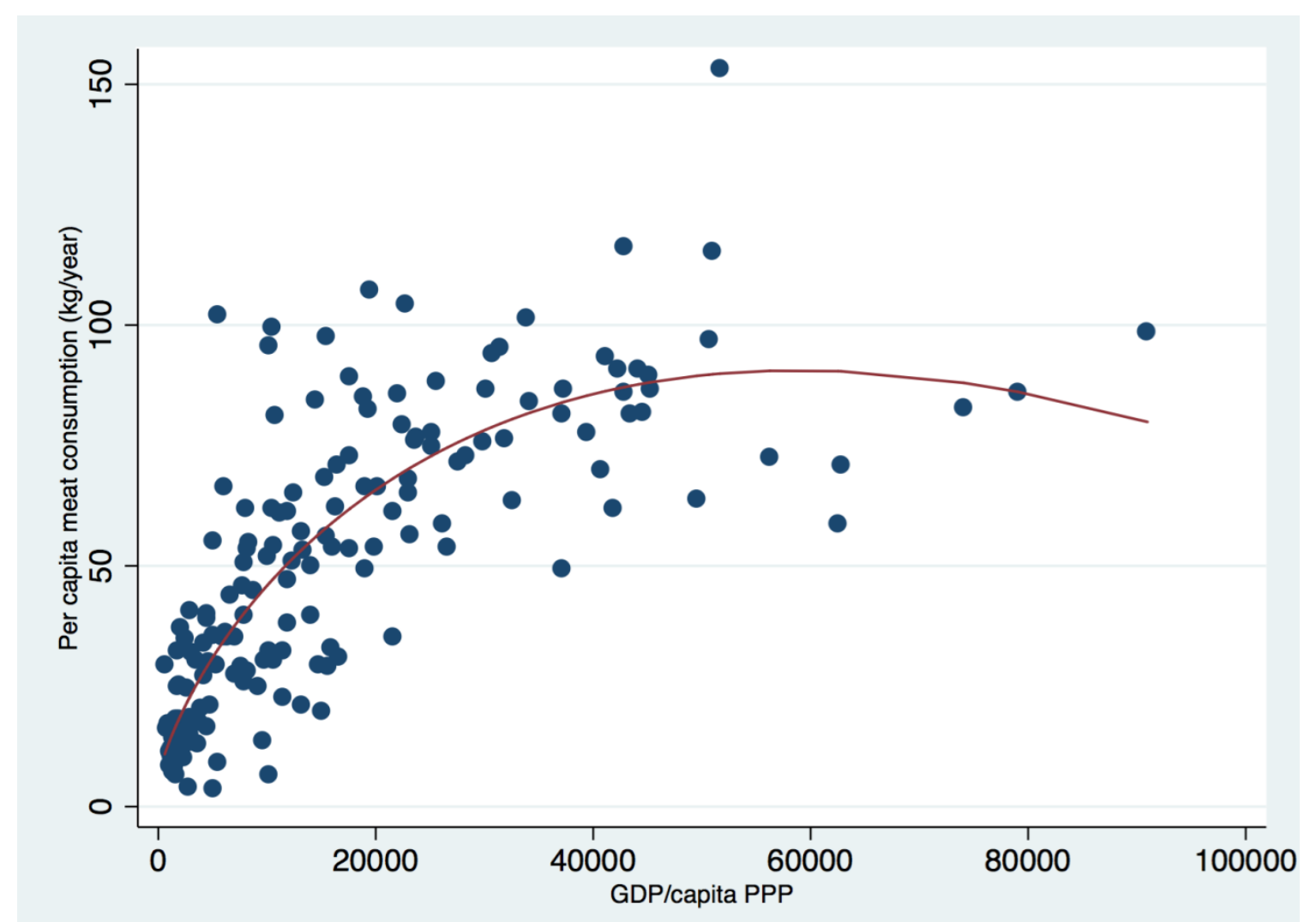

Source: Compiled by author based on FAOSTAT (meat) and World Development Indicators (GDP/capita PPP, constant 2011 international dollars)

Note: 2013 statistics for both per capita meat consumption and per capita GDP. Meat consumption based on FAO food supply statistics, meaning that numbers include meat wasted or otherwise not consumed by humans. The curve in the figure was fitted with a fractional polynomial. The figure includes all countries and territories for which FAO provides meat statistics, with a few exceptions where GDP data was unavailable (see table 3). For the purpose of illustration and due to extreme GDP values, the small semi-autonomous region of Macao was excluded. A full list of countries/territories can be found in table 3 in the appendix.

What makes people, as a general trend, eat more meat when they get more money, beyond the fact that they can now afford to do so? And why are there such big variations between countries?

\footnotetext{
${ }^{5}$ In FAO statistics, food supply refers to the food available to consumers (production plus imports minus exports). It does not mean that the food is eaten. Therefore it likely exaggerates final consumption.
} 
There is a need for more in-depth, empirically grounded studies of the seemingly global tendency towards eating more meat as income increases.

In analysing meat consumption this paper draws on the by now rich tradition of empirically grounded consumption research. This field of inquiry has traditionally had a certain inclination towards mature capitalist countries, although several recent studies of consumption among 'emerging middle classes' may indicate a growing field (e.g. Sahakian, 2014; Hansen, Nielsen and Wilhite, 2016; Gregson and Ferdous, 2015; McEwan, Hughes and Bek, 2015). While consumption research remains heavily shaped by disciplines, outside mainstream economics a shared point of analytical departure may be seen in an appreciation of consumption as a fundamentally social phenomenon and a related rejection of the rational, self-maximizing consumer as the appropriate starting point for understanding this phenomenon. As decades of consumption research has shown, individual choice is a small part of the complex processes that determine consumption patterns (see e.g. Douglas and Isherwood, 1979; Bourdieu, 1984; Shove, 2010; Warde, 2005; Wilhite, 2008). Furthermore, a general recent trend has been a turn away from the post-modern preoccupation with symbols and signs towards inconspicuous consumption, everyday life and social practices. This 'practice turn', which also influences this paper, approaches consumption as parts of, or moments in, shared social practices, which are, in turn, shaped by social, bodily and material elements (for overviews, see Warde, 2005, 2014, 2016).

However - and even more so in contexts of rapid economic development and transformation supply-side factors are vital to understanding changing consumption patterns. While this fact is certainly not rejected by consumption research, supply-side factors have tended to receive scant attention (although see Rinkinen, Shove and Smits, 2017). So-called systems of provision (Fine and Leopold, 1993; Fine, Heasman and Wright, 1996; Fine, 2002, 2013) make goods available and materialise social practices. Although not alone sufficient to explain consumption patterns, they represent a vital part of the equation. This paper argues for analysing consumption through provision and practices, and after considering overall development trends in Vietnam, takes changes in the provision of meat as a starting point for understanding how escalating consumption has been possible in the country.

\section{Development, agricultural change and meat consumption in Vietnam}


Vietnam has attracted significant academic and development policy interest due to the many achievements of the doi moi ('renovation') reforms (see Van Arkadie and Mallon, 2003; Masina, 2006; Mishra, 2011). The economic development achieved since the reforms were officially initiated in 1986 has seen Vietnam move from one of the poorest countries in Asia to a “development success story" (Mishra, 2011) and an "emerging economy” (see Hansen, 2015). Over the last three decades Vietnam's economy has grown steadily at a high rate, with GDP almost quintupling between 1990 and 2010 (Mishra, 2011). Even more impressively, extreme poverty has been reduced from more than 70 per cent of the population in the mid-' 80 s (Banik and Hansen, 2016) to 3.1 per cent in 2014 (World Bank, 2017, using \$1.90 a day, 2011 PPP). Furthermore, Vietnam has moved from a war-torn and isolated country in the 1980s and early '90s to an important trade partner and a lucrative emerging market for foreign investors today.

Agricultural development has played a crucial role in the reform process, both in feeding a growing population, but crucially also as a central part of export-led development strategies and rural poverty alleviation. With the largely failed collectivisation of agriculture during the planned economy, food was scarce and Vietnam became dependent on imports (Marzin and Michaud, 2016). As a symbol of the success of doi moi, Vietnam developed from a rice importer to the second largest rice exporter in the world. Output increased tremendously and Vietnam became an important agricultural exporter, with agricultural exports forming a central part of GDP growth (Marzin and Michaud, 2016).

For many Vietnamese, doi moi has involved a transformation from extreme scarcity to relative abundance. And for most Vietnamese, reforms have involved significant improvements in living standards, reflected for example in life expectancy increasing from 67.4 years in 1980 to 75.8 years in 2015, and infant mortality rates decreasing from 46.8 per 1,000 live births in 1980 to 17.3 per 1,000 in 2015 (World Bank, 2017). Improved nutrition has represented an important part of these development achievements. Table 1 shows how from the year doi moi was implemented (1986) until 2013, daily per capita calorie intake increased by an average of about 33 per cent. Table 1 also clearly reveals a strong increase in consumption of animal products. In the same period, calories from vegetal products increased by about 14 per cent (1904 kcal to $2170 \mathrm{kcal}$ ), while calories from animal products increased by 357 per cent ( $161 \mathrm{kcal}$ to $575 \mathrm{kcal})$. This increase was mainly due to a drastic rise in the consumption of pork (96 kcal to $344 \mathrm{kcal}$ ) (FAOSTAT). 
Table 1 Daily kcal per capita, Vietnam, 1961-2013

\begin{tabular}{|l|c|c|c|c|c|c|c|c|c|c|c|c|}
\hline & 1961 & 1966 & 1971 & 1976 & 1981 & 1986 & 1991 & 1996 & 2001 & 2006 & 2011 & 2013 \\
\hline $\begin{array}{l}\text { Grand } \\
\text { total }\end{array}$ & 1907 & 1916 & 1957 & 1890 & 2004 & 2065 & 1856 & 2018 & 2299 & 2483 & 2716 & 2745 \\
\hline $\begin{array}{l}\text { Vegetal } \\
\text { products }\end{array}$ & 1769 & 1768 & 1829 & 1787 & 1880 & 1904 & 1691 & 1798 & 2004 & 2046 & 2141 & 2170 \\
\hline $\begin{array}{l}\text { Animal } \\
\text { products }\end{array}$ & 138 & 148 & 128 & 104 & 124 & 161 & 166 & 221 & 294 & 437 & 575 & 575 \\
\hline
\end{tabular}

Sources: Adopted from Marzin and Michaud, 2016; updated with numbers from FAOSTAT

According to FAO numbers, yearly meat consumption per capita in Vietnam increased from $14.26 \mathrm{~kg}$ in 1986 to $55.22 \mathrm{~kg}$ in 2013 (FAOSTAT). Figure 2 shows that the bulk of meat consumption is represented by pork, but the strongest relative increase was in the consumption of beef and poultry. Pork consumption per capita tripled between 1993 and 2015, while beef consumption increased six-fold, and poultry consumption rose seven-fold, despite the slump following the outbreak of avian flu in 2011. Also the consumption of other animal products has increased significantly. The clearest example is milk consumption, which increased almost twelve-fold from an annual $1.4 \mathrm{kgs}$ per capita in 1986 to $16.4 \mathrm{kgs}$ per capita in 2013 (FAOSTAT). These are all dramatic increases. And the magnitude of the total consumption is even more dramatic when it is borne in mind that Vietnam's population in the same period increased from 60 million to 90 million (World Bank, 2017).

It should, furthermore, be noted here that these numbers do not include the consumption of dog meat and 'wild meat'. Both are widespread practices (see Avieli, 2011; Drury, 2011), so the total meat consumption is considerably higher than these numbers indicate. 
Figure 2: Meat consumption per capita, Vietnam, 1993-2015

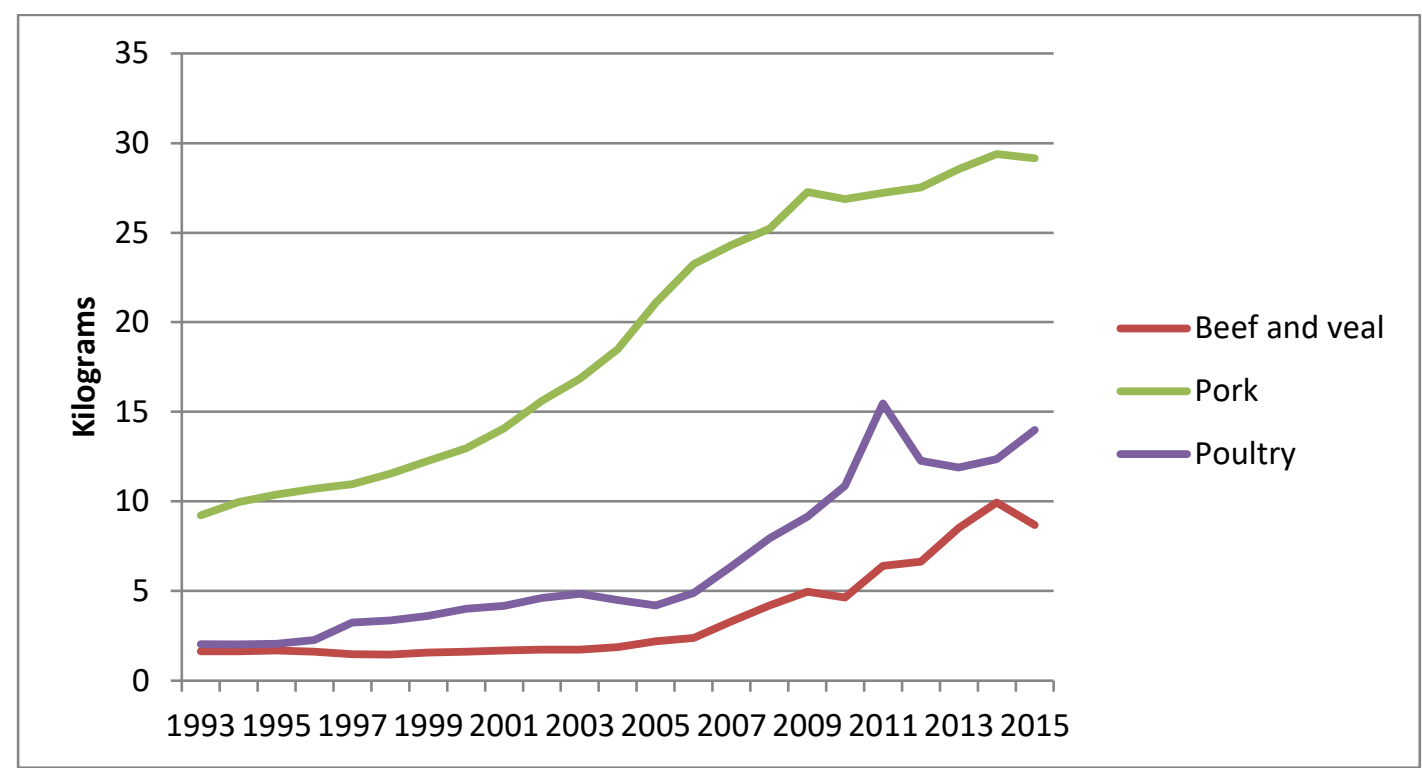

Source: Compiled by author based on numbers from OECD (2017)

Vietnam consumes more meat compared to other Southeast Asian countries at similar levels of per capita GDP (see table 2) and much more than the Southeast Asian average of $29.41 \mathrm{kgs}$ (FAOSTAT). Indeed, Vietnam consumes more meat compared to most countries in the world at similar levels of GDP (see table 3). Meat consumption in Vietnam was in 2013 (the latest year with available FAO numbers) at the level of Malaysia, which had a GDP per capita more than four times higher than Vietnam's. Taking income into account Vietnam also has a relatively high level of meat consumption compared to China. The trends over time have been similar in the two countries, although China in 2013 had a GDP per capita more than double that of Vietnam. Given that these two countries have a culture of dog and wild meat consumption, the total meat consumption numbers should again be much higher. 
Table 2 GDP/capita, urbanisation rates and meat consumption in SE Asia and China, 2013

\begin{tabular}{|l|c|c|c|}
\hline & $\begin{array}{l}\text { GDP/capita } \\
\text { (current int. \$) }\end{array}$ & $\begin{array}{l}\text { Urban population } \\
\text { (\% of total) }\end{array}$ & $\begin{array}{l}\text { Meat, food supply } \\
\text { quantity/kgs/capita }\end{array}$ \\
\hline Brunei Darussalam & 81,827 & 77 & 85.99 \\
\hline Singapore & 81,288 & 100 & $-*$ \\
\hline Malaysia & 24,034 & 73 & 56.25 \\
\hline China & 12,368 & 53 & 61.82 \\
\hline Indonesia & 9,980 & 52 & 13.55 \\
\hline Philippines & 6,527 & 45 & 35.1 \\
\hline Vietnam & 5,300 & 32 & 55.22 \\
\hline Lao PDR & 4,999 & 36 & 21.07 \\
\hline Myanmar & 4,613 & 33 & 39.03 \\
\hline Cambodia & 3,070 & 20 & 13.21 \\
\hline Timor-Leste & 2,113 & 31 & 37.17 \\
\hline
\end{tabular}

Note: *FAO does not provide numbers for meat consumption in Singapore.

Source: World Development Indicators; FAOSTAT.

From the numbers presented so far in the paper it becomes clear that Vietnam in many ways fits into the story of the livestock revolution and the nutrition transition. But Table 2 also shows that affluence and urbanisation alone cannot explain diverging levels of meat consumption in the region. Vietnam is not wealthy and is among the least urbanised countries in Southeast Asia. It is also unlikely that 'Western' influences on diets are stronger in Vietnam than in neighbouring countries. The following section will investigate the main factors contributing to increasing meat consumption in Vietnam.

\section{Increasing meat consumption in Vietnam - the main factors}

Starting on the provisioning side with the rather obvious factor of improved availability of meat, I move on to discuss changes in food practices, looking into the meat intensification of traditional dishes; the influences of new, meat intensive foreign food practices and the increasing prevalence of eating out. I then dig deeper into the meanings of meat consumption in Vietnam today, focusing on associations between meat and development and the statusenhancing potentials of (certain forms of) meat consumption. 


\subsection{Factor 1: Provisioning meat: Increased availability and affordability}

Although there have long been discussions about the primacy of production versus consumption (see, for example, Miller, 1995), needless to say, consumption cannot take place without available products. Arguably, improved access to goods and improved means to acquire them represents a significant part of how development is experienced by most people. While there were informal channels for getting meat during the days of the planned economy with its rationing system, meat scarcity was the reality for most Vietnamese before doi moi. Even in cities it is common for many Vietnamese to remember a time not that long ago when meat was a luxury to be enjoyed mainly during the lunar New Year (Tet) celebrations and at weddings. This was indeed the role of meat in the diet of most Vietnamese also before the communist days, at least for the rural majority (Peters, 2012). The stories of meat scarcity stand in sharp contrast to the burgeoning meat markets and supermarket shelves today, as summarised by this statement by a retired woman who lived through those changes:

When I was born it was peace, but we didn't have any meat. Very little. When I was a teenager it was war and we had to leave the city to avoid the bombs and there was also no meat. Maybe in the end of the month or once every two weeks my parents would send something for us to eat, but no meat. When I was a grown-up we had a bit more meat. And then we opened up with $d o i$ moi, and they brought in meat from everywhere. And now I think there's too much meat!

(Interview, March, 2017).

The increased availability of meat is due to two main factors. First of all, agricultural output and processing have increased dramatically with doi moi, as already indicated above. The story of rice production is well known (e.g. Marzin and Michaud, 2016), but the increases in parts of the livestock sector have been equally astounding. Production in the livestock sector grew faster than production in crops between 1990 and 2013, and the share of the livestock sector of total agricultural production increased from 20 per cent in 1995 to 27 per cent in 2013 (OECD, 2015). Pig meat production increased from 625,000 tonnes in 1986 to more than 3.3 million tonnes in 2014. Beef and buffalo meat in the same period increased from 136,000 tonnes to 387,000 tonnes a year, and chicken production from 96,000 tonnes to 633,000 tonnes (FAOSTAT). The goal of the government is for total meat production to reach 8 million tonnes by 2020 (see $\mathrm{Vu}$ Hoang Yen et al., 2017). As an integral agricultural sector for both domestic food production and rural incomes, the livestock sector has been subject to a variety of government support 
programmes (OECD, 2015; for an overview of recent policies, see Tran Cong Thang and Bui Thi Viet Anh, 2016).

Interestingly, the Vietnamese livestock sector has remained mainly small-scale, as indeed has most of Vietnam's agriculture (OECD, 2015; see also Rigg, Salamanca and Thompson, 2016). This feature has, however, been changing as a result of government policies favouring farm specialization, agricultural industrialisation and the up-scaling of production (Cesaro, 2016), and a recent process of consolidation in the farming sector has been observable (OECD, 2015). Also, smallholders have to an increasing extent - with the help of authorities and international organisations - introduced more efficient production processes such as stall feeding systems instead of grazing, which have, in turn, led to higher quality meat (see Stür et al., 2013). Many smallholders also now serve as contract farmers to large corporations such as Charoen Pokphand (CP) from Thailand and Japfa Comfeed from Indonesia (interview, agricultural value chain expert, Hanoi, October, 2017). An associated development has also been a very rapid rise in the domestic production of maize (GSO, 2017b) as well as in imports of maize and soy beans for the livestock sector, with imports now comprising 60 per cent of all animal feed (Cesaro, 2016).

These changes in domestic agricultural output are obviously a very large part of the explanation for why meat consumption has increased so rapidly. But for poultry and beef demand has outgrown domestic supply (IPSOS Business Consulting, 2016). This brings us to the second part of the provision story: international trade. Vietnam has opened its market for imports from a range of large meat producing countries. Figure 3 shows the total value of imports and from the five largest exporters of meat to Vietnam which together accounted for close to 85 per cent of overall meat imports in 2015. 
Figure 3 Meat imports, Vietnam

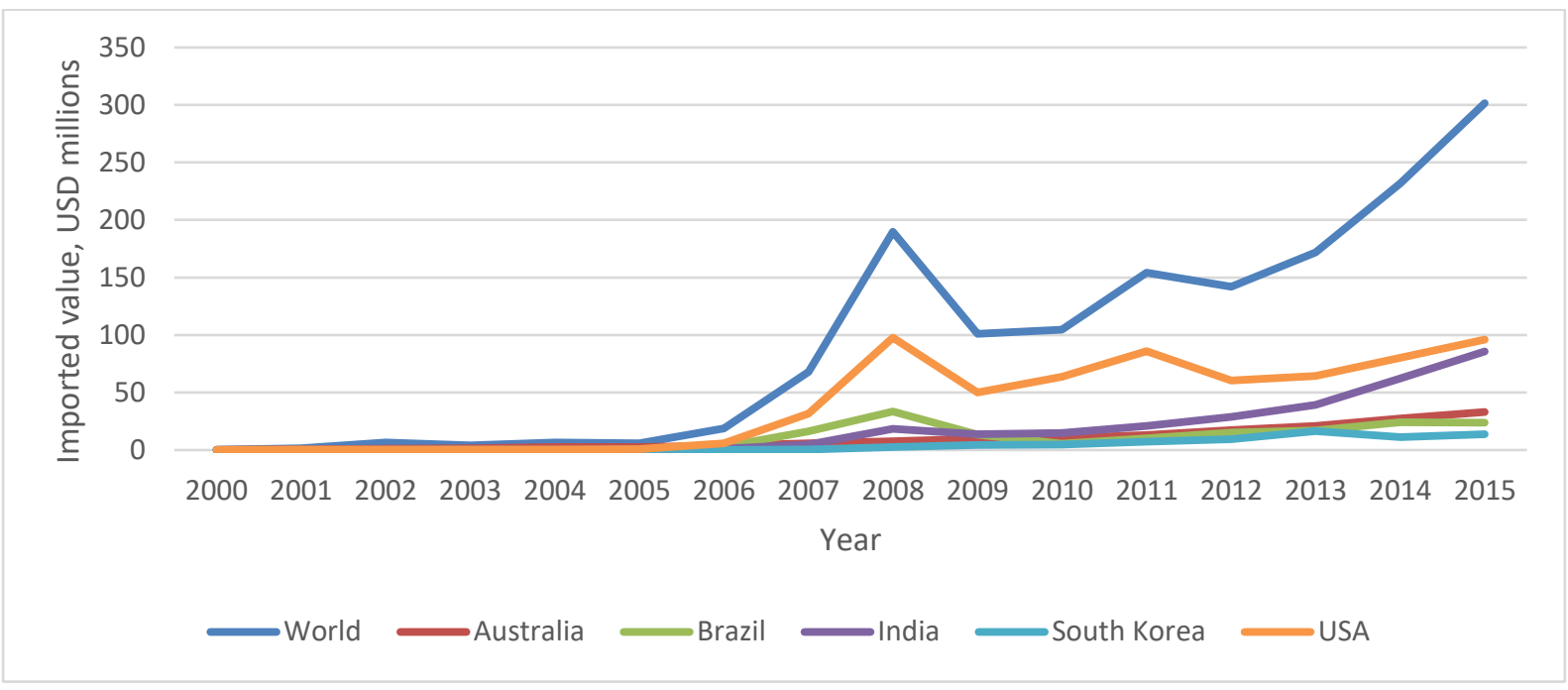

Source: Compiled by author based on UN Comtrade (2017)

More than a third of imports in 2015 was frozen beef, mainly from India, but also the US and Australia; and more than a third comprised meat and offal from poultry, mainly from the US, but also Brazil and Korea. As the graph shows, these imports took off when Vietnam joined the WTO in 2007. Vietnam also exports meat, mainly pork to Hong Kong (54.5 million USD in 2015) and Malaysia (8.8 million USD in 2015) and poultry to China (12.3 million USD in 2015) (UN Comtrade, 2017), but imports account for 3.5 times the value of exports (UN Comtrade, 2017).

A new trend is to import live animals from abroad for slaughter in Vietnam (see Figure 4). This is mainly the case for live cattle from Australia, and some from Thailand, which together represent almost all of the imported value. On the other hand, Vietnam exports cattle and pigs to, in particular, Laos. Exports of live pigs to China have been significant, but came to a stop in 2017 when China stopped imports of live pigs due to putative quality concerns. 


\section{Figure 4 Live animal imports, Vietnam}

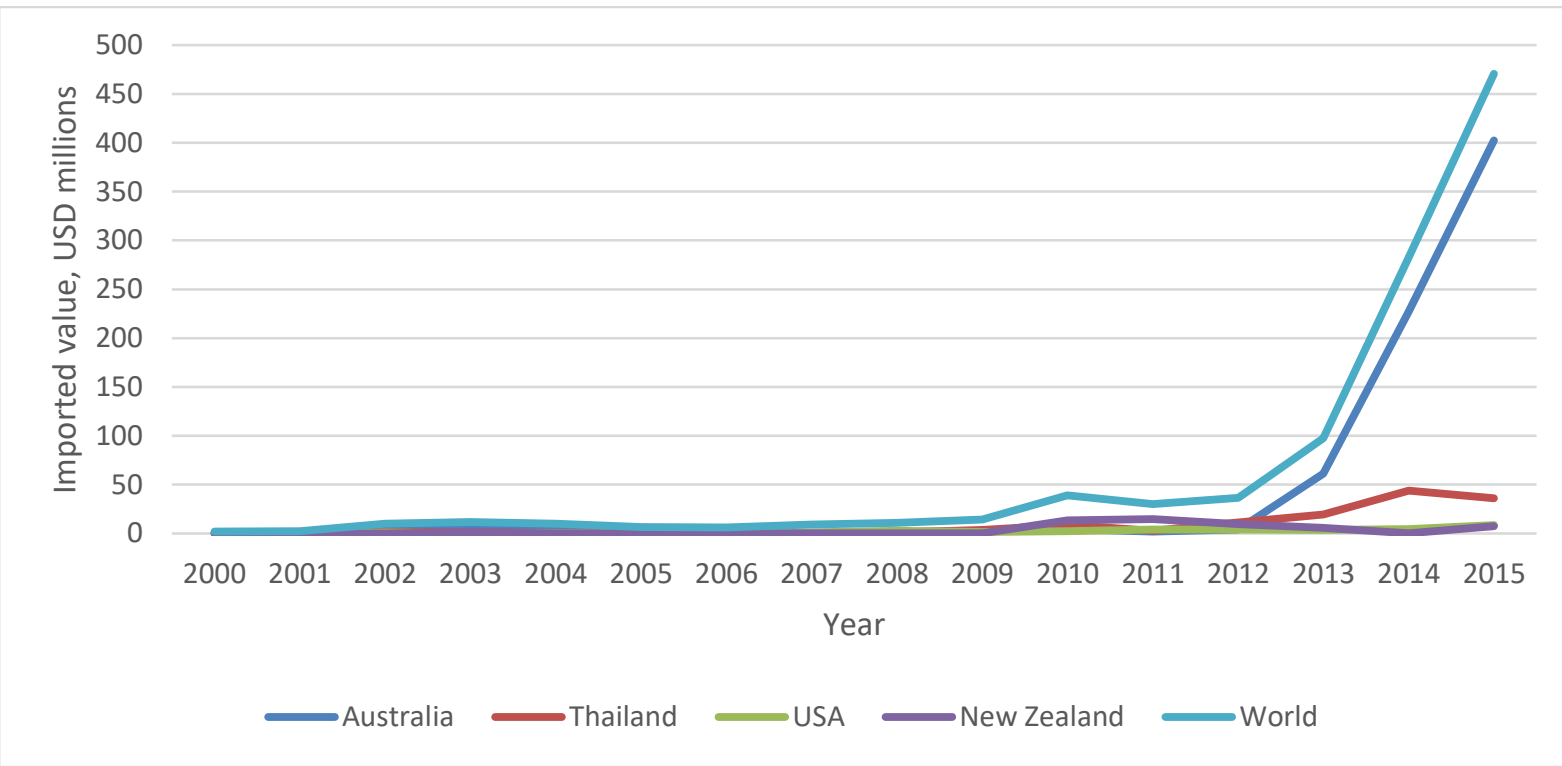

Source: Compiled by author based on UN Comtrade (2017)

The increased availability of meat is obviously necessary for meat consumption to increase, combined with the fact that this has made meat much more affordable to consumers. Pork production has indeed recently seen a crisis of oversupply due to both the halt in exports to China and increasing imports to Vietnam, which has pushed down prices significantly (see for example VnExpress, 2017; Ho Binh Minh 2017). The increase in supply has to some extent been driven by increasing demand from a gradually more affluent population, and recently the expectation of a growing market for Vietnamese pigs and pork products in China, the world's largest market for pork.

There are structural changes along entire livestock supply chains in Vietnam. Farming has, as stated above, remained mostly small-scale, but the government is now intent on luring more investors to agriculture. The feed industry is increasingly dominated by imports and multinational corporations - small-scale neighbourhood slaughtering in urban areas has been replaced by larger sites outside the cities, and individual traders on motorbikes delivering meat to wet markets are facing competition from companies transporting meat by trucks to restaurants and supermarkets. A certain supermarketisation is doubtless taking place in Vietnam's cities, with government backing (Wertheim-Heck, Vellema and Spaargaren, 2015), although many traditional wet markets are so far proving resilient. The retailing sector opened for foreign investments in January 2009, as part of Vietnam's WTO commitments (Wertheim- 
Heck, Vellema and Spaargaren, 2015). Alongside the large supermarkets, there has been a significant surge, in recent years, in smaller mini-marts, such as VinMart+. As a response to increasing concerns about quality and cleanliness among consumers, corporations such as the powerful Vingroup have started 'farm-to-fork' initiatives where they control the entire value chain. It seems likely that this is one of the business models the government will be supporting in coming years, and among many of my interviewees VinMart's food was indeed highlighted as safer than others due to this control. While small minimarts sell chilled meat, the large supermarkets usually have a wide variety of choices, including fresh, chilled and frozen meat. In addition, an increasing number of processed meat products, such as sausages and premade meals, are available in supermarkets.

In sum, the changes in the systems of provision for meat represent an important facilitator for escalating meat consumption. Vietnam is able to produce more meat, and alongside imports and new retail structures, the availability of meat has increased dramatically. Supply is nevertheless a necessary but insufficient factor for explaining consumption, and exaggerating the role of supply removes agency from consumers. Many household interviewees reflected on the rapid changes in the food scene, and particularly on the fact that they no longer knew where the meat came from. There were different opinions as to whether safe shops, trusted market vendors or supermarkets were the best or safest places to buy meat, and some also talked of informal trade networks to get "clean meat" directly from the countryside. This brings us to consumers and food practices. What lies behind the increased shopping for and eating of meat? How has meat consumption increased in everyday Vietnamese food practices?

\subsection{Factor 2: Meat intensification of food practices}

This second factor can be separated into two main issues: The meat intensification of 'traditional' meals and dishes and the influence of foreign meat intensive dishes and eating practices.

First of all, meat is a part of a wide range of what are considered 'traditional' Vietnamese dishes, although this is probably due to alterations over time rather than a true reflection of what daily diets historically have involved for most Vietnamese (see Peters, 2012). Nevertheless, broths for most of the noodle soups, such as the famous and highly popular breakfast dish pho, are cooked on animal parts, and meat or fish (or both) is considered a necessary part of a meal, 
together with rice, soup (canh), and greens and vegetables (see also Avieli, 2012). These dishes, however, used to involve very small amounts of meat, if any at all. By contrast, today the pho, like most other noodle dishes, is often served with generous portions of beef or chicken. In many pho stalls the customer is able to choose from many different parts of the animal, as well as different ways of preparing them. This came up in a conversation with a retired professional and her daughter. The mother, referring to pho, stated that "before, people put very little meat in it. Now there's so much meat" (translated from Vietnamese). The daughter agreed, and added the example of a popular pork and rice vermicelli dish: "Bun cha also. Before, very little meat. But now it's like you just eat meat, basically". (Interview, March 2017). Similarly, meat is now standard in lunch and dinner meals, although still usually as one of several dishes. These changes to dishes and meals can be seen as a form of rather subtle changes to the materiality of everyday practices, and although difficult to quantify are likely to be an important reason for increasing meat consumption.

The reasons for this intensification are many, including increased supply of meat and, a point further developed below, the positive associations meat has for many people. For the street food dishes an element of competition also plays a role, as street kitchens compete to offer the best deal and the tastiest dishes.

In addition to the meat intensification of what are considered typical Vietnamese dishes, a range of foreign-influenced eating practices and dishes are relevant. Foreign influences on Vietnamese eating practices are nothing new (see Peters, 2012). The famous banh $m i^{6}$ is a French-Vietnamese hybrid, and even pho, the Vietnamese 'national dish', is probably a Chinese-Vietnamese hybrid emerging only about one hundred years ago (Peters, 2010). But market reforms have brought a new range of foreign influences, and while the impact of foreign influences on local food practices has often been exaggerated in popular and academic accounts (see for example Wilk, 2006 for discussion), these influences do represent an important factor here.

While meat is part of typical meals in Vietnam, foreign food practices that are increasing in popularity in cities are pushing meat to the centre of the meal. KFC was the first of the transnational food giants to establish businesses in Vietnam, opening its first outlet in 1997.

\footnotetext{
${ }^{6}$ Banh mi literally means bread. The version that is filled with herbs, meat and sauce is now famous in many countries outside Vietnam.
} 
There are now $140 \mathrm{KFC}$ restaurants in Vietnam, in a total of 19 cities. ${ }^{7}$ While KFC is probably the most popular, American franchises like Burger King and McDonald's entered later, as did East Asian franchises like Jollibee from the Philippines and Lotteria from Japan. Pizza and pasta has also grown highly popular in cities, led by foreign franchises such as Pizza Hut and Domino's, national hybrids such as Pepperoni's and Al Fresco and local independent restaurants.

At the higher end of the price scale, steak houses have recently been emerging in cities. There, large portions of beef usually represent the main part of the meal. While the steak houses are in many cases North or South American-inspired, eating beef also exists in a street food hybrid known as bit tet, and served with fries on plastic tables. Some Eastern meat intensive practices have also become highly popular. Japanese and Korean BBQ restaurants are among the most popular around for those who can afford it. Some of these are highly meat intensive, and many of them tend to advertise imported meat, often from the US or Australia. In an interesting example of globalisation and its associated processes of hybridisation, I interviewed the Vietnamese owner of a big and very popular Korean BBQ restaurant in Hanoi. First of all, she said that she would adapt the Korean-inspired tastes to local taste buds by using Vietnamese herbs and spices to better suit her young, Vietnamese customer base. She then explained that all the meat she used was imported from Brazil, "because now consumers prefer things that come from outside, and also the imported meat is sometimes cheaper, actually a lot cheaper than meat produced in Vietnam”. The imported meat was seen as a sign of quality, she said, and added that customers probably did not know that frozen meat imported from Brazil was cheaper than locally produced meat (Interview, March, 2017, translated from Vietnamese). Another East Asian influence is found in the success story of instant noodles. With a wide variety of national and foreign brands available, usually including some processed meat or seafood, Vietnam ranks as the fourth biggest market and the second biggest per capita consumer of instant noodles in the world. ${ }^{8}$

Although foreign food and foreign food outlets are gaining traction, they usually represent an addition to a diet consisting mainly of traditional Vietnamese food usually including rice or noodles. Interviewees frequently reported that they found Western food "too creamy" and not suitable to Vietnamese taste buds. Nevertheless, most of my household interviewees would fairly regularly eat foreign food, especially when eating out. And I have been frequently told

\footnotetext{
${ }^{7}$ https://kfcvietnam.com.vn/en/about-us.html

${ }^{8}$ https://instantnoodles.org/en/common_en/pdf/EN_MARKET_VOLUME_3LG_A4_2016.pdf
} 
that children love Western food like pizza, pasta and hamburgers, possibly foreshadowing future dietary changes when a generation more accustomed to foreign tastes grows up. The following quote from a 30-year-old dance instructor illustrates the combination of foreign and Vietnamese food: "My son is 5 years old. And he really likes traditional food [...]. My mum cooks very well, so he really likes traditional Vietnamese food. And KFC" (Interview, March, 2017, translated from Vietnamese). Or the following quote from a self-employed man in his late thirties, reflecting the dietary diversity among the Vietnamese urban middle class: "My wife loves Western food. My son loves Western food and my daughter loves Japanese food. And I love Vietnamese food" (Interview, April, 2017, translated from Vietnamese).

Only my most foreign-inspired interviewees, such as a few of those married to foreigners, would challenge the centrality of rice and noodles in their diets. And few would venture to cook foreign food at home. Instead, many would experiment with foreign tastes when going out to eat, which takes me to my next contributing factor.

\subsection{Factor 3: Eating out}

The third factor is closely related to the second, but deserves a separate section. Eating away from home is seen as an important part of the nutrition transition (Popkin et al., 2012), and over the last decade Vietnam has seen an immense increase in the prevalence of eating out. As Figure 5 shows, the average spending on meals outside of home increased almost ten-fold between 2002 and 2012. Consumption expenditure in general increased significantly in this period, and Figure 6 shows that the average percentage of total consumption expenditure spent on meals outside has also increased significantly. Although the richest 20 per cent spend almost twice as much as the next income quintile and almost eight times the amount of the poorest quintile, spending on meals outside has increased significantly among all income segments. The figures also show that urban households spend much more on eating out than rural households, both in absolute terms and as a percentage of income, although the spending by rural households has seen the strongest relative increase. 
Figure 5: Monthly expenditure on eating out by income quintiles, 2002 and 2012

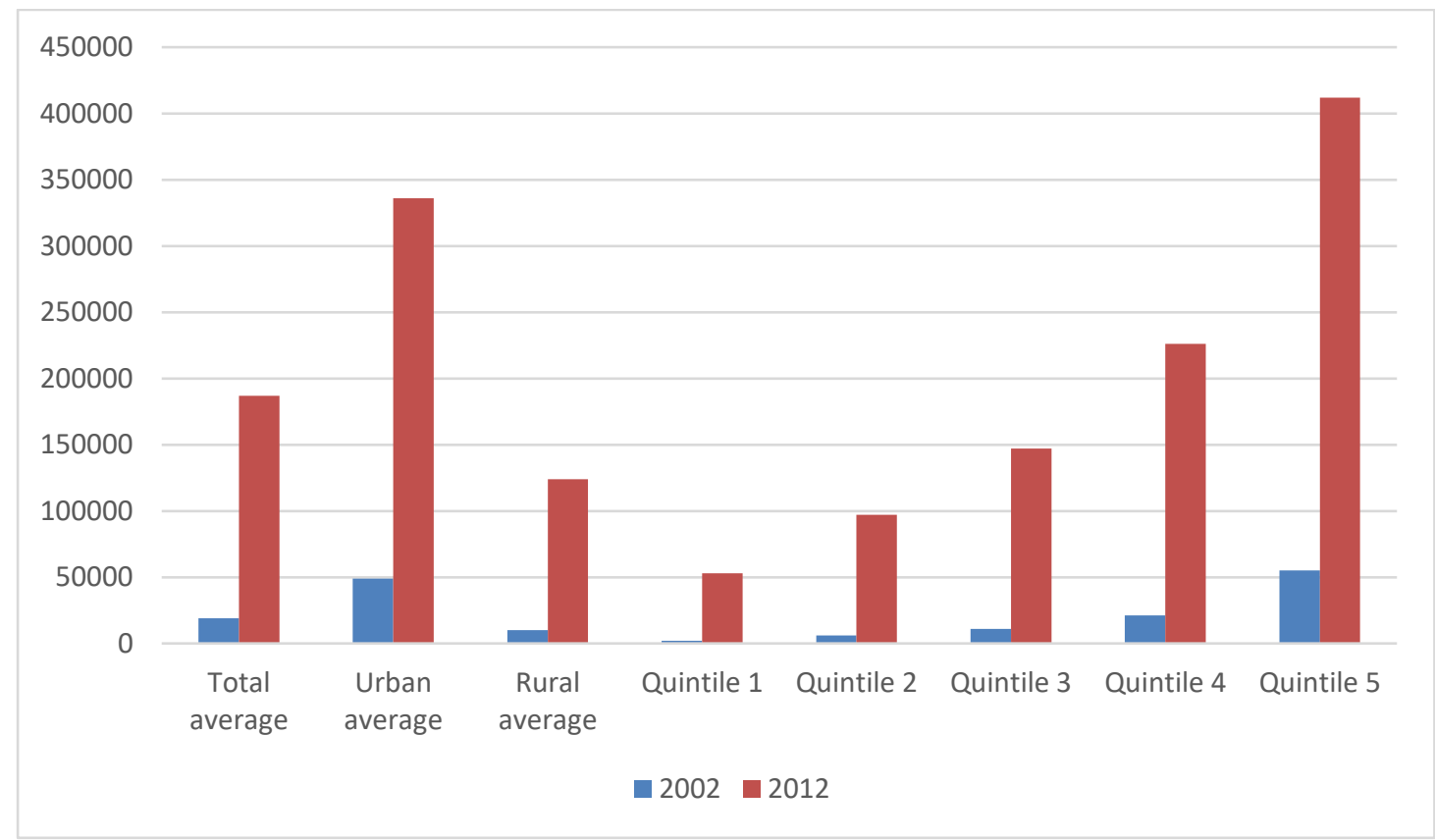

VND, current prices. Source: Compiled by author based on GSO (2012): Household living standard survey 2012

Figure 5: Percentage of consumption expenditure spent on eating out by income quintiles, 2002 and 2012

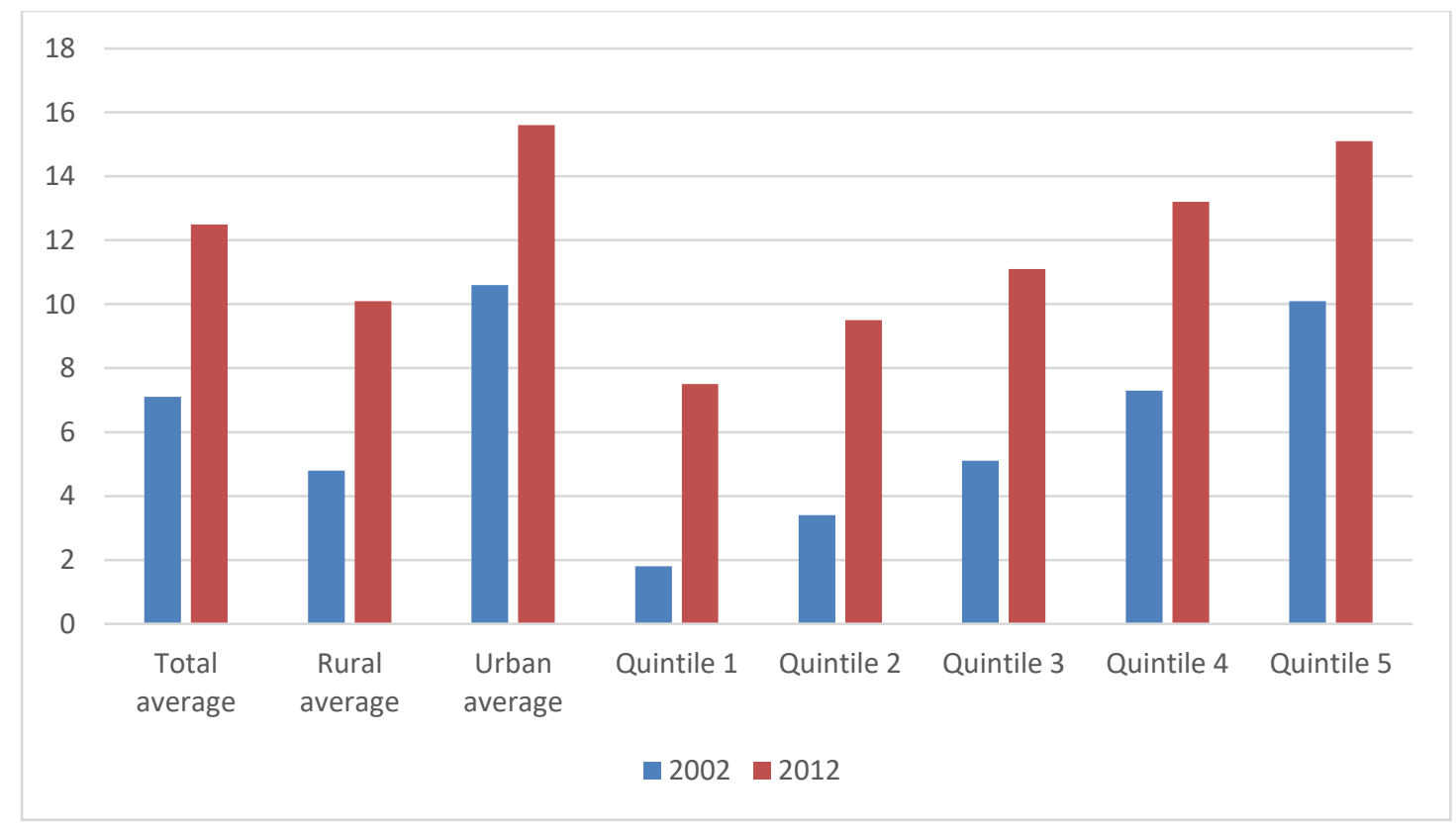

Source: Compiled by author based on GSO (2012): Household living standard survey 2012 
There are reasons to believe that meals outside involve more meat than meals at home, both because of the structure of the typical family meal with a remaining strong focus on rice and vegetables, and because of the more meat intensive food practices introduced in restaurants and fast food outlets. A look at the numbers from the 2012 national household survey shows that reported average meat consumption was $21.6 \mathrm{~kg}$ in 2012 versus $15.6 \mathrm{~kg}$ in 2002 (GSO, 2012). Using FAOSTAT data, as discussed above, total meat supply was $55.2 \mathrm{~kg}$ per capita in 2012 versus $27.8 \mathrm{~kg}$ per capita in 2002. The reasons for the sharp difference between households' reported consumption and total meat supply can be many. First, meat can be wasted instead of reaching the consumer. It is possible that more food was wasted in 2012 than in 2002, perhaps as part of new and more wasteful value chains. Furthermore, consumption in the tourism sector is significant. Vietnam had 2.6 million international arrivals in 2002 and more than 6.8 million in 2012 (World Bank, 2017). Still, as meat eaten outside the home is not reported in the household survey, there are reasons to believe that this discrepancy also reflects the fact that Vietnamese in general eat less at home and more out than they did before (see Figures 5 and 6 ).

Why do people eat out more? Macro-economic processes and everyday practices co-shape this trend. More restaurants and increasing incomes are obvious factors, but equally important are changes in the dynamics of everyday life. Different work hours, longer commuting distances and a more diverse social life are characteristics of the changes associated with economic development - and more so in cities than in rural areas - that make meals outside more convenient and more popular than cooking at home. Smaller households and the declining importance of the family meal are also important factors. Vietnam, like many other countries in the region, also has a very large number of inexpensive eateries serving quality food, which usually also offer a take-away service. These eateries and eating practices are now under threat in cities as local and national authorities continue moulding Vietnam in their vision of a 'modern and civilized' society. The same is the case for traditional markets, which remain the main outlet for food in Vietnam. Changes in living and working situations combined with changes in mobility practices with increasing car ownership instead of motorbikes (Hansen, 2017a) and government policies in favour of supermarketisation are paving the way for new forms of shopping practices with a wider availability of fresh and processed meat products. A large number of food scares have further accelerated this trend, although also contributing to the expansion of small 'safe food' shops and informal food networks from farm to city (see Hansen, 2017b). 
The tendency towards eating out was reflected in most of my interviews with middle class households, especially among the younger interviewees. Some of them, especially if they were unmarried but lived away from their parents - a relatively new phenomenon in Vietnam reported eating almost every meal outside or through take away or home delivery. The combination of a plethora of street kitchens serving affordable and tasty dishes and materialisations of Hanoi's "system of moto-mobility" (Hansen, 2017a) in the form of extensive motorbike delivery services contribute towards the popularity of these food practices.

Also married couples reported eating out often, especially for breakfast and lunch. And many cherish this possibility, since it reduces the workload at home and provides access to a wide variety of dishes. Eating out also contributes to another part of Vietnam's nutritional changes: Vietnamese are eating less rice (FAOSTAT). As a young, unmarried, woman somewhat triumphantly told me, referring to urban, (upper) middle-class women like her: "we don't cook, so [...] we are not forced to eat rice" (Interview, March, 2017).

\subsection{Factor 4: Meat representing development and distinction}

I believe it is fairly safe to say a significant proportion of Vietnamese view eating meat as healthy. As a food conscious interviewee in her early thirties told me: "People think calcium comes from milk [and] protein, basically energy, comes from meat. That's the basic understanding." (Interview, March 2017). This kind of attitude towards meat is of course prevalent in a very large number of countries and cultures. What distinguishes Vietnam from many other countries is that the change from extreme scarcity to abundance has been so rapid. The access to meat, I argue, is seen as a central part of development. This is important, since it has led to a positive association between increased meat consumption and increased living standards. Many of my interviewees touched upon this topic, and a few quotes can illustrate this. For example in this conversation with a journalist in her thirties:

Author: It seems meat consumption is increasing very fast in Vietnam.

Informant: Yes, it's absolutely true. I think it's also related to [...] history. Because in the past, Vietnam was a developing country and the income was quite low. So people usually bought vegetables instead of meat, because it's cheaper. Even now, in rural areas, people usually buy vegetables instead of meat if they don't have enough money. And rice. So meat can be considered [...] as something higher income people can consume. [...] So you can have more meat if you get more income. That's the history of Vietnam, I think. [...] I think we still have a gap to fill, a potential to increase consumption. 
(Interview, April 2017).

Or, like these reflections from a self-employed man in his late thirties:

Meat represents a bit of money. We want to show that we are able to provide our kids with a bit of meat on the tray. Before, there was war, and we didn't have anything, not meat, not anything. So people who have gone through that period want to make it up for their kids.[...] And they also want to make it up for themselves.[...]. Even after the war, there was a long period when we had little to eat. But after doi moi and all the new things that followed, we can afford it, we can make up for everything we have gone through. So when we can afford it we pay a lot for meat. It has already been 30 years since doi moi, so the habit of eating meat has had a long time to settle. Eating meat is now a new habit that we have.

(Interview, April, 2017, translated from Vietnamese).

This point should be qualified by taking into account that many urbanites are, for different reasons, trying to moderate their intake of meat. Among my interviewees, some talked about the intake of red meat as unhealthy. Indeed, health concerns were the most common explanation given for limiting meat intake, although many would eat white meat instead. A few of my younger interviewees had also decided to go fully vegetarian.

While there is social distinction involved in choosing not to eat meat within certain social segments, the same is certainly true for eating lots of meat. Some meat practices, such as eating dog meat and wild meat, are considered masculine and can also be status-enhancing (Avieli, 2011; Drury, 2011), although many among especially the young, urban middle class consider such practices outdated and even cruel. Eating the reproductive organs of certain animals is believed to be libido-enhancing. I have, for example, participated in men only goat meat feasts, where congealed blood was served as a starter and reproductive organs were part of the 'hot pot' (lau) main dish. Vietnam is furthermore internationally infamous for eating and using parts of rare animals due to their perceived medicinal capacities, including being a major destination for illegal rhino horns from Africa (Truong, Dang and Hall, 2016).

Also more foreign-inspired food practices come with significant social status attached. Eating at foreign fast food outlets is popular among young people, and has become very popular for celebrating children's birthday parties (which is also a largely imported practice). Among older and wealthier segments of the population, going out for a proper steak meal is considered appropriate. Instead of downing beer and rice wine as is common in more traditional meat feasts, alongside steak imported red wine is carefully sipped. This is a way of eating that demands different social skills. These restaurants are sites for quiet conversations, and eating must be 
done with a knife and fork instead of chopsticks. Most of all, however, these eating practices demand economic capital. Eating a full steak combined with red wine easily costs the average monthly salary of a worker, and it is not unusual to also pay the bill for one's guests. As is common for practices that are inaccessible to the vast majority of the population, this is something many among the wealthier strata of the Vietnamese society enjoy indulging in. To take one example, the young upper middle class woman who earlier stated she was no longer forced to eat rice, said her favourite dish was beef. Interestingly, she also exclaimed "I love lamb", a quite untypical statement in Vietnam where lamb is uncommon. But the fact that she could afford to have beef and lamb as her favourite food was of course also a clear expression of her privileged status, interestingly resembling the French colonialists in Peters' (2012: 164) account who would serve leg of lamb in Saigon to declare their Frenchness and difference from the locals.

\section{Eating a capitalist transformation: practices and provision}

The discussion so far shows that Vietnam has in many ways experienced developments along the lines of what is described as the nutrition transition and the livestock revolution. Indeed, when it comes to the latter, Vietnam is perhaps the clearest example in all of Southeast Asia. The factors presented above also to some extent support the standard explanatory factors of increasing affluence, urbanisation and foreign (Western) influences for understanding increasing meat consumption. The factors identified here however also show that in the case of Vietnam, a contextualised analysis of consumption through systems of provision and everyday practices brings necessary nuance to the standard explanation and identifies additional important factors.

Starting with urbanisation, Vietnam has high levels of meat consumption and a relatively low percentage of the population living in cities. The discussion above has shown that developments in Vietnam partly support the association between urbanisation and meat-intensive lifestyles, mainly due to the increased prevalence of meals away from home. However, Vietnamese cities are also home to an emerging popularity of meat-less lifestyles, and Vietnam's comparatively low urbanisation levels and high meat consumption levels clearly indicate that urbanisation is insufficient to explain surging meat consumption. 
Affluence is an obvious factor, and incomes in Vietnam have increased very rapidly in the last three decades (e.g. World Bank, 2012). Crucially, however, changes in systems of provision of meat have at the same time made meat much more affordable. This has happened through enormous increases in output in livestock production - often, as Schneider (2017) has documented in China, with government support - as well as increased global and regional economic integration. Hawkes (2006) argues that the globalisation of agri-food systems and opening for foreign investment in food retailing are important explanatory factors for the nutrition transition. For Vietnam, this is a valid point. Trade and investment liberalisation has opened for imports of cheap meat and feed from abroad, as well as for the establishment of foreign fast food chains in the country. These processes can usefully be understood as part of the spatial expansion of capitalism. Although the extent to which Vietnam's self-proclaimed "socialist market economy" is capitalist is subject to some discussion (see Hansen, 2015), it is obvious that capitalist, and state capitalist, actors in production, feed, processing and retail have played a central role in escalating meat consumption. This includes the spread of franchises, which in many ways are a symptom of market-liberalism combined with monopoly capitalism. People eat at these places for a wide variety of reasons and attribute very different meanings to them in different countries and cultures (see for example Watson, 2006), but they remain manifestations of capitalist market logics 'from farm to fork'. Foreign influences such as these are clearly important factors for increasing meat consumption, but in Vietnam 'Eastern' dietary influences are as important as 'Western' in terms of meat intensity. Furthermore, an equally important dimension is the meat-intensification of local meals and dishes, an often gradual and inconspicuous process.

Everyday practices are deeply affected by the multi-scalar processes associated with capitalist economic development. In turn, practices and demand structures clearly co-shape the development of systems of provision. Domestic and foreign meat producers and retailers obviously pay close attention to, and contribute to fuelling, the demand and desire for meat. But supply, increasing income, urbanisation and foreign influences do not automatically make people consume more meat. As Appadurai (1986: 29) puts it, demand "emerges as a function of a variety of social practices and classifications, rather than a mysterious emanation of human needs, a mechanical response to social manipulation [...], or the narrowing down of a universal and voracious desire for objects to whatever happens to be available". In Vietnam, changes in food practices towards more eating out and more meat-intensive cooking, as well as more supermarket shopping, are strengthening and are made possible by changes in systems of 
provision towards more restaurants, more fast food chains, more supermarkets and more and more affordable meat in traditional markets and supermarkets. In addition, the valuation among major parts of the population of more meat as a symbol of better living standards, as well as the social distinction involved in particular forms of meat consuming behaviour, strongly feed into the meat-intensity of food practices.

\subsection{Meat cultures}

The social valuation of meat is an example of a culture of meat consumption that is clearly stronger in some countries than others. Vietnam's high level of meat consumption compared to per capita income levels is something it shares with its giant neighbour to the north, China. Thus there may be grounds for a deeper cultural and geographical reading of the evolution of livestock production and meat consumption that is beyond the scope of this paper. This is strengthened by the fact that Hong Kong had the highest, and Macao among the highest, levels of per capita meat consumption in the world in 2013 (FAOSTAT, see also Table 3). China and Vietnam share a long, although conflicted, history and many cultural traits (see for example Goscha, 2016). The two countries are probably more similar to each other - in terms of politics, economy, cultural practices and societal organisation - than each of them are to any other country.

In terms of systems of provision, one of the traits Vietnam and China share is a history of smallscale pig breeding, although traditionally, as Schneider (2017: 89) argues for the case of China, "pigs were more valuable alive than dead" due to their functions at the farm. With reforms, the production expanded and people were able to consume more than their few servings of meat a year. In China, with the gradual marketisation of the economy, large-scale production following capitalist agricultural production principles started replacing small-scale farming as a way to increase productivity and enhance government control $^{9}$ (Schneider, 2017; MacLachlan, 2015b). This is, to some extent, happening in Vietnam as well, where there is now a clear tendency towards blaming problems in the meat production sector on the ostensible unruliness of smallholder farming. Instead, the government is providing support and incentives for large capital to invest in agriculture, although highly sensitive and complex issues of land ownership might hamper this. Upscaling is certainly in line with global trends, bearing in mind that an

\footnotetext{
${ }^{9}$ A process that has a very different history in Hong Kong (Chan and Miller, 2015).
} 
estimated 75 per cent of pig (and poultry) production globally comes from industrial systems (Herrero et al., 2015).

My point is that not only development per se, but particular forms of development and food regimes in favour of cheap, mass-produced meat through domestic production and imports, create the necessary backdrop for rapidly increasing meat consumption. But China and Vietnam also share very rapid transformations from communist planned economies to market economies and associated changes to everyday practices, including food practices. An understanding of everyday life and the practices through which meat reaches people's shopping bags, plates and mouths, is needed in order to understand why and how people actually eat more meat.

\section{Conclusions}

Many parts of the world, and particularly Eastern parts of Asia, are seeing rapid increases in the consumption of meat. In Vietnam, meat consumption has increased very quickly since the doi moi reforms and the rapid economic development that has followed. This paper has shown that the standard explanations of affluence, urbanisation and foreign dietary influences are contributing factors to these changes, but they are not sufficient explanations. I have argued for an approach to meat consumption that takes into account systems of provision without neglecting the importance of everyday practices and the agency of consumers. Furthermore, I have argued that escalating meat consumption in Vietnam needs to be understood as part of the spatial expansion of capitalism and an overall capitalist transformation, including the development of a consumer society. Rather than the inevitable outcome of increasing income and urbanisation, these trends are made possible by capitalist development processes favouring mass production and mass consumption of meat.

In sum, the systems of provision for meat in Vietnam have changed. Initially away from collective farming towards smallholder farming geared for profits from domestic and international markets. And later towards larger-scale industrial agriculture, combined with more efficient transport and more outlets in the shape of markets, supermarkets, mini-marts, street kitchens, restaurants, and fast food joints. Meanwhile, and partly due to these processes, food practices have been 'meatified'. I have argued parts of this process take a conspicuous shape, like eating steak at fancy restaurants, while other parts are largely inconspicuous, such as gradually larger amounts of meat in portions of pho. Furthermore, in a country where even 
the richest segments of the population remember extreme scarcity, meat is for many still one of the defining factors of progress.

Macro-economic processes play a vital part in shaping people's everyday lives and consumption patterns. This being said, consumers are not dupes, and consumption patterns are shaped in the encounter with social practices and preferences. Vietnam has not seen revolutionary changes in diets, at least not so far. It has, however, seen incremental access to meat and an increasing uptake of meat into food practices.

In addition, since Vietnam and China both have high levels of meat consumption relative to income, and Hong Kong and Macao have among the highest levels of per capita meat consumption in the world, there are likely to be relevant cross-border cultural and geographical factors that this paper has not sufficiently addressed. Comparative studies of countries in the region could shed more light on this factor. In general, since a further increase in global meat consumption is deeply unsustainable, more empirically grounded research is needed on the economic, social and cultural factors contributing to meatification. 


\section{References}

Appadurai, A., 1986. Introduction: commodities and the politics of value, in: Appadurai, A. (Ed.), The Social life of things : commodities in cultural perspective. Cambridge University Press, Cambridge, pp. XIV, $329 \mathrm{~s}$.

Avieli, N., 2011. Dog meat politics in a Vietnamese town. Ethnology 50 (1), 59-78.

Avieli, N., 2012. Rice Talks: Food \& Community in a Vietnamese Town. Indiana University Press, Bloomington.

Banik, D., Hansen, A., 2016. The Frontiers of Poverty Reduction in Emerging Asia. Forum for Development Studies.

Bourdieu, P., 1984. Distinction : a social critique of the judgement of taste. Routledge \& Kegan Paul, London.

Cesaro, J.-D., 2016. Une croissance sans limite? Vers une nouvelle géographie de l'élevage au Vietnam. Université Paris Ouest Nanterre-La Défense, Paris.

Chan, KW., Miller, B., 2015. Capitalist pigs : Governmentality, subjectivities, and the regulation of pig farming in colonial Hong Kong, 1950-1970. Environment and Planning D: Society and Space 33 (6), $1022-1042$.

Delgado, C., Rosegrant, M., Steinfeld, H., Ehui, S., Courbois, C., 1999. Livestock to 2020: The next food revolution, IFPRI Food, Agriculture, and the Environment Discussion Paper. IFPRI, Washington D.C. Delgado, C.L., 2003. Rising Consumption of Meat and Milk in Developing Countries Has Created a New Food Revolution. The Journal of Nutrition 133 (11), 3907S-3910S.

Douglas, M., Isherwood, B., 1979. The world of goods. Basic Books, New York.

Drury, R., 2011. Hungry for success: Urban consumer demand for wild animal products in Vietnam. Conservation and Society 9 (3), 247-257.

Fine, B., 2002. The world of consumption: the material and cultural revisited. Routledge, London. Fine, B., 2013. Consumption Matters. Ephemera 13 (2), 217-248.

Fine, B., Leopold, E., 1993. The world of consumption. Routledge, London.

Fine, B., Heasman, M., Wright, J., 1996. Consumption in the age of affluence: The world of food. Routledge, London

Goscha, C., 2016. The Penguin History of Modern Vietnam, Penguin Books, UK.

Gregson, N., Ferdous, R., 2015. Making space for ethical consumption in the South. Geoforum 67, 244-255.

Grigg, D., 1995. The pattern of world protein consumption. Geoforum 26 (1), 1-17.

GSO - General Statistics Office of Vietnam 2012. Household Living Standard Survey 2012, Hanoi:

Statistical Publishing House.

GSO - General Statistics Office of Vietnam, 2017a. Number of farms by kinds of manufacturing sector and by province, http://www.gso.gov.vn/default en.aspx?tabid=778

GSO - General Statistics Office of Vietnam, 2017b. Production of main annual crops, http://www.gso.gov.vn/default en.aspx?tabid=778

Halkier, B., Jensen, I., 2011. Methodological challenges in using practice theory in consumption research. Examples from a study on handling nutritional contestations of food consumption. Journal of Consumer Culture 11 (1), 101-123.

Hansen, A., 2015. The best of both worlds? The power and pitfalls of Vietnam's development model, in: Hansen, A., Wethal, U. (Eds.), Emerging Economies and Challenges to Sustainability: Theories, Strategies, Local Realities. Routledge, London and New York.

Hansen, A., 2017a. Hanoi on wheels: emerging automobility in the land of the motorbike. Mobilities $12(5), 628-645$.

Hansen, A., 2017b. Vietnam's New Food Crisis. IAPS Dialogue. 15.12.2017.

https://iapsdialogue.org/2017/12/15/vietnams-new-food-crisis/

Hansen, A., Nielsen, K.B., Wilhite, H., 2016. Staying Cool, Looking Good, Moving Around:

Consumption, Sustainability and the 'Rise of the South'. Forum for Development Studies. 
Hawkes, C., 2006. Uneven dietary development: linking the policies and processes of globalization with the nutrition transition, obesity and diet-related chronic diseases. Globalization and Health 2, 4. Henchion, M., McCarthy, M., Resconi, V.C., Troy, D., 2014. Meat consumption: Trends and quality matters. Meat Science 98 (3), 561-568.

Herrero, M., Wirsenius, S., Henderson, B., Rigolot, C., Thornton, P., Havlík, P., de Boer, I., Gerber, P.J., 2015. Livestock and the Environment: What Have We Learned in the Past Decade? Annual Review of Environment and Resources 40, 177-202.

Ho Binh Minh 2017 https://e.vnexpress.net/news/business/vietnam-to-chop-pork-imports-inmission-to-save-pig-farmers-bacon-3579000.html

IPSOS Business Consulting, 2016. Vietnam Meat Market. IPSOS Business Consulting, HCMC, Vietnam. Kearney, J., 2010. Food consumption trends and drivers. Philosophical Transactions of the Royal Society B: Biological Sciences 365 (1554), 2793-2807.

Kristensen, L., Støier, S., Würtz, J., Hinrichsen, L., 2014. Trends in meat science and technology: The future looks bright, but the journey will be long. Meat Science 98 (3), 322-329.

Kvale, S., Brinkmann, S., 2009. Interviews: learning the craft of qualitative research interviewing. Sage, Los Angeles, Calif.

Marzin, J., Michaud, A., 2016. Evolution of Rural Development Strategies and Policies: Lessons from Vietnam, in: ART-Dev (Ed.), ART-Dev Working papers, Montpellier.

Masina, P.P., 2006. Vietnam's development strategies. Routledge, Oxon UK ; New York.

Mathijs, E., 2015. Exploring future patterns of meat consumption. Meat Science 109 (Supplement C), 112-116.

McEwan, C., Hughes, A., Bek, D., 2015. Theorising middle class consumption from the global South: A study of everyday ethics in South Africa's Western Cape. Geoforum 67, 233-243.

MacLachlan, I., 2015a. Evolution of a revolution: meat consumption and livestock production in the developing world, in: Emel, J., Neo, H. (Eds.), Political Ecologies of Meat. Routledge, London.

MacLachlan, I., 2015b. The Livestock Transition, Peri-Urban Agricultural Land-Use and Urbanization in China. Paper presented to the $3^{\text {rd }}$ Conference on China Urban Development, East China Normal University, Shanghai, 6 June 2015.

Miller, D., 1995. Consumption as the Vanguard of History: A Polemic by Way of an Introduction, in: Miller, D. (Ed.), Acknowledging consumption: a review of new studies. Routledge, London.

Mishra, D. 2011. Vietnam Development Report 2012: Market Economy for a Middle-Income Vietnam. Washington, DC: World Bank

Neo, H., Emel, J. 2017. Geographies of Meat: Politics, Economy and Culture. Routledge, Oxon. OECD, 2017. Meat consumption (indicator). doi: 10.1787/fa290fd0-en (Accessed on 27 October 2017)

OECD, 2015. Agricultural Policies in Viet Nam 2015, OECD Publishing, Paris.

http://dx.doi.org/10.1787/9789264235151-en

OECD/FAO, 2016. OECD-FAO Agricultural Outlook 2016-2025. OECD Publishing, Paris.

Peters, E.J., 2010. Defusing Phở: Soup Stories and Ethnic Erasures, 1919-2009. Contemporary French and Francophone Studies 14 (2), 159-167.

Peters, E.J., 2012. Appetites and Aspirations in Vietnam: Food and Drink in the Long Nineteenth Century. Altamira Press, Lanham.

Pica-Ciamarra, U., Otte, J. 2011. The "Livestock Revolution": rhetoric and reality. Outlook on Agriculture 40 (1), 7-19.

Popkin, B.M., 1993. Nutritional patterns and transitions. Population \& Development Review 19 (1), 138-157.

Popkin, B.M., Adair, L.S., Ng, S.W., 2012. Global nutrition transition and the pandemic of obesity in developing countries. Nutr Rev 70 (1), 3-21.

Rigg, J., Salamanca, A., Thompson, E.C., 2016. The puzzle of East and Southeast Asia's persistent smallholder. Journal of Rural Studies 43 (Supplement C), 118-133.

Rinkinen, J., Shove, E., Smits, M., 2017. Cold chains in Hanoi and Bangkok: Changing systems of provision and practice. Journal of Consumer Culture 0 (0), 1469540517717783. 
Sahakian, M., 2014. Keeping Cool in Southeast Asia. Palgrave Macmillan, Basingstoke, p. 264.

Sans, P., Combris, P., 2015. World meat consumption patterns: An overview of the last fifty years (1961-2011). Meat Science 109 (Supplement C), 106-111.

Schneider, M., 2017. Wasting the rural: Meat, manure, and the politics of agro-industrialization in contemporary China. Geoforum 78, 89-97.

Schneider, M., Sharma, S., 2014. China's Pork Miracle? Agribusiness and Development in China's Pork Industry, in: Policy, I.f.A.a.T. (Ed.), Global Meat Complex: The China Series, Washington D.C.

Sharma, S., 2014. The Need for Feed: China's Demand for Industrialized Meat and Its Impacts, Global Meat Complex: The China Series.

Shove, E., 2010. Beyond the ABC: climate change policy and theories of social change. Environment and Planning A 42, 1273-1285.

Steinfeld, H., Gerber, P., Wassenaar, T., Castel, V., Rosales, M., de Haan, C., 2006. Livestock's Long Shadow: Environmental Issues and Options. FAO, Rome.

Stür, W., Khanh, T.T., Duncan, A., 2013. Transformation of smallholder beef cattle production in Vietnam. International Journal of Agricultural Sustainability 11 (4), 363-381.

Tran Cong Thang and Bui Thi Viet Anh (2016). List of Main Policies for Vietnam's Livestock Sector. FFTC Agricultural Policy Platform. http://ap.fftc.agnet.org/ap db.php?id=702 Last accessed 13.09.2017

Truong, V. D., Dang, V. H. N., Hall, C. M. 2016. The marketplace management of illegal elixirs: Illicit consumption of rhino horn. Consumption Markets \& Culture, 19 (4), 353-369

UN Comtrade, 2017. UN Comtrade trade statistics, https://comtrade.un.org/data, last accessed 27.10.2017

Van Arkadie, B., Mallon, R., 2003. Viet Nam: a transition tiger? Asia Pacific Press, The Australian National University.

VnExpress 2017 https://e.vnexpress.net/news/business/vietnam-to-export-pork-to-china-amidsupply-glut-3591147.html

Vranken, L., Avermaete, T., Petalios, D., Mathijs, E., 2014. Curbing global meat consumption:

Emerging evidence of a second nutrition transition. Environmental Science \& Policy 39 (Supplement C), 95-106.

Vu Hoang Yen, 2017. Overview of Vietnam's food security policies, in: Petersen, E. (Ed.), Vietnam food security policy review. ACIAR Monography no. 196. Australian Centre for International Agricultural Research, Canberra.

Warde, A., 2005. Consumption and Theories of Practice. Journal of Consumer Culture 5 (2), 131-153. Warde, A., 2014. After taste: Culture, consumption and theories of practice. Journal of Consumer Culture 14 (3), 279-303.

Warde, A., 2016. The practice of eating. Polity, Cambridge.

Watson, J.L., 2006. Golden Arches East : McDonald's in East Asia, 2nd ed. ed. Stanford University Press, Stanford, Calif.

Weis, T., 2013a. The Ecological Hoofprint: The Global Burden of Industrial Livestock. Zed Books, London.

Weis, T., 2013b. The meat of the global food crisis. The Journal of Peasant Studies 40 (1), 65-85. Wertheim-Heck, S.C.O., Vellema, S., Spaargaren, G., 2015. Food safety and urban food markets in Vietnam: The need for flexible and customized retail modernization policies. Food Policy 54, 95-106. Wilhite, H., 2008. New thinking on the agentive relationship between end-use technologies and energy-using practices. Energy Efficiency 1 (2), 121-130.

Wilk, R. 2006. Home cooking in the global village: Caribbean food from buccaneers to ecotourists, Berg, Oxford.

World Bank (2017). World Development Indicators. Last accessed 10.11.2017

World Bank (2012). Well Begun, Not yet Done: Vietnam's Remarkable Progress on Poverty Reduction and the Emerging Challenges, Hanoi: World Bank. 


\section{Appendix}

Table 3 List of countries and territories, meat consumption/capita and GDP/capita

\begin{tabular}{|c|c|c|}
\hline & Meat consumption/capita & GDP/capita PPP \\
\hline Afghanistan & 12,33 & 1814 \\
\hline Albania & 61,96 & 10504 \\
\hline Algeria & 21,07 & 13253 \\
\hline Angola & 36,13 & 6185 \\
\hline Antigua and Barbuda & 85,07 & 18863 \\
\hline Argentina & 107,24 & 19482 \\
\hline Armenia & 45,71 & 7728 \\
\hline Australia & 116,23 & 42920 \\
\hline Austria & 90,87 & 44162 \\
\hline Azerbaijan & 31,1 & 16593 \\
\hline Bahamas & 104,2 & 22715 \\
\hline Bangladesh & 4,11 & 2836 \\
\hline Barbados & 68,13 & 15335 \\
\hline Belarus & 89,08 & 17656 \\
\hline Belgium & 69,93 & 40781 \\
\hline Belize & 50,48 & 7903 \\
\hline Benin & 25,19 & 1935 \\
\hline Bermuda & 96,97 & 50669 \\
\hline Bolivia & 66,38 & 6091 \\
\hline Bosnia and Herzegovina & 32,21 & 10269 \\
\hline Botswana & 28,94 & 15568 \\
\hline Brazil & 97,58 & 15430 \\
\hline Brunei Darussalam & 85,99 & 79070 \\
\hline Bulgaria & 53,72 & 15997 \\
\hline Burkina Faso & 11,72 & 1518 \\
\hline Cabo Verde & 35,12 & 5964 \\
\hline Cambodia & 13,21 & 2966 \\
\hline Cameroon & 13,35 & 2815 \\
\hline Canada & 90,75 & 42336 \\
\hline Central African Republic & 29,45 & 598 \\
\hline Chad & 12,01 & 2007 \\
\hline China & 61,05 & 11951 \\
\hline Chile & 85,69 & 21998 \\
\hline Colombia & 50,79 & 12296 \\
\hline Congo & 29,38 & 5317 \\
\hline Costa Rica & 49,99 & 14035 \\
\hline Côte d'Ivoire & 15,01 & 2880 \\
\hline Croatia & 66,3 & 20153 \\
\hline Cuba & 53,94 & 19962 \\
\hline Cyprus & 75,58 & 29843 \\
\hline Czechia & 72,83 & 28380 \\
\hline Denmark & 81,87 & 44564 \\
\hline Djibouti & 18,35 & 2876 \\
\hline Dominica & 51,94 & 10008 \\
\hline Dominican Republic & 47,2 & 11888 \\
\hline Ecuador & 53,98 & 10665 \\
\hline Egypt & 30,47 & 9814 \\
\hline El Salvador & 29,04 & 7636 \\
\hline Estonia & 58,54 & 26148 \\
\hline Ethiopia & 7,06 & 1326 \\
\hline Fiji & 39,59 & 7978 \\
\hline Finland & 77,53 & 39428 \\
\hline France & 86,76 & 37367 \\
\hline French Polynesia & 101,1 & $\mathrm{~N} / \mathrm{A}$ \\
\hline Gabon & 70,81 & 16503 \\
\hline Gambia & 6,41 & 1599 \\
\hline Georgia & 27,98 & 8254 \\
\hline Germany & 85,94 & 42914 \\
\hline Ghana & 17,44 & 3807 \\
\hline Greece & 76,6 & 23746 \\
\hline Grenada & 60,91 & 11263 \\
\hline Guatemala & 27,39 & 7005 \\
\hline Guinea & 10,39 & 1235 \\
\hline
\end{tabular}




\begin{tabular}{|c|c|c|}
\hline Guinea-Bissau & 16,33 & 1396 \\
\hline Guyana & 43,79 & 6683 \\
\hline Haiti & 17,99 & 1629 \\
\hline Honduras & 34 & 4178 \\
\hline Hong Kong & 153,12 & 51671 \\
\hline Hungary & 65,04 & 23020 \\
\hline Iceland & 93,33 & 41097 \\
\hline India & 3,69 & 5074 \\
\hline Indonesia & 13,55 & 9643 \\
\hline Iran & 32,88 & 15965 \\
\hline Iraq & 19,67 & 15078 \\
\hline Ireland & 86,69 & 45257 \\
\hline Israel & 95,15 & 31435 \\
\hline Italy & 84,04 & 34220 \\
\hline Jamaica & 61,76 & 8026 \\
\hline Japan & 49,45 & 37149 \\
\hline Jordan & 44,79 & 8757 \\
\hline Kazakhstan & 67,84 & 22973 \\
\hline Kenya & 14,32 & 2683 \\
\hline Kiribati & 32,17 & 1831 \\
\hline Korea, South & 63,61 & 32549 \\
\hline Korea, North & 13,98 & $\mathrm{~N} / \mathrm{A}$ \\
\hline Kuwait & 82,88 & 74085 \\
\hline Kyrgyzstan & 32,07 & 3121 \\
\hline Lao PDR & 21,07 & 4830 \\
\hline Latvia & 61,1 & 21599 \\
\hline Lebanon & 39,63 & 14075 \\
\hline Lesotho & 24,6 & 1640 \\
\hline Liberia & 16,3 & 819 \\
\hline Lithuania & 77,65 & 25148 \\
\hline Luxembourg & 98,53 & 90950 \\
\hline Macao & 119,45 & 135319 \\
\hline Macedonia & 38,16 & 11878 \\
\hline Madagascar & 14,12 & 1364 \\
\hline Malawi & 11,25 & 1062 \\
\hline Malaysia & 56,25 & 23224 \\
\hline Maldives & 32,41 & 11455 \\
\hline Mali & 24,75 & 1794 \\
\hline Malta & 86,62 & 30142 \\
\hline Mauritania & 30,36 & 3566 \\
\hline Mauritius & 53,47 & 17629 \\
\hline Mexico & 62,23 & 16316 \\
\hline Moldova & 39,86 & 4542 \\
\hline Mongolia & 81,1 & 10720 \\
\hline Montenegro & 84,51 & 14551 \\
\hline Morocco & 35,02 & 6996 \\
\hline Mozambique & 8,5 & 1035 \\
\hline Myanmar & 39,03 & 4458 \\
\hline Namibia & 24,97 & 9259 \\
\hline Nepal & 12,21 & 2164 \\
\hline Netherlands & 89,49 & 45191 \\
\hline New Caledonia & 82,37 & $\mathrm{~N} / \mathrm{A}$ \\
\hline New Zealand & 101,4 & 33841 \\
\hline Nicaragua & 29,87 & 4619 \\
\hline Niger & 17,2 & 874 \\
\hline Nigeria & 9,2 & 5479 \\
\hline Norway & 70,89 & 62799 \\
\hline Oman & 61,92 & 41924 \\
\hline Pakistan & 16,41 & 4464 \\
\hline Panama & 66,39 & 19057 \\
\hline Paraguay & 53,61 & 8227 \\
\hline Peru & 22,52 & 11430 \\
\hline Philippines & 35,1 & 6307 \\
\hline Poland & 76,08 & 23555 \\
\hline Portugal & 88,35 & 25655 \\
\hline Romania & 49,4 & 19009 \\
\hline Russian Federation & 74,82 & 25144 \\
\hline Rwanda & 8,01 & 1539 \\
\hline Saint Kitts and Nevis & 79,07 & 22399 \\
\hline Saint Lucia & 99,49 & 10529 \\
\hline Saint Vincent and Grenadines & 95,55 & 10193 \\
\hline Samoa & 102,2 & 5490 \\
\hline
\end{tabular}




\begin{tabular}{|c|c|c|}
\hline Sao Tome and Principe & 16,08 & 2786 \\
\hline Saudi Arabia & 63,75 & 49538 \\
\hline Senegal & 15,78 & 2193 \\
\hline Serbia & 53,32 & 13295 \\
\hline Sierra Leone & 10,68 & 1655 \\
\hline Slovakia & 53,87 & 26581 \\
\hline Slovenia & 71,38 & 27630 \\
\hline Solomon Islands & 13,81 & 2033 \\
\hline South Africa & 64,92 & 12446 \\
\hline Spain & 94,04 & 30677 \\
\hline Sri Lanka & 6,48 & 10239 \\
\hline Sudan & 27,05 & 4177 \\
\hline Suriname & 56,05 & 15419 \\
\hline Swaziland & 25,89 & 7899 \\
\hline Sweden & 81,57 & 43476 \\
\hline Switzerland & 72,32 & 56253 \\
\hline Taiwan & 77,69 & $\mathrm{~N} / \mathrm{A}$ \\
\hline Tajikistan & 34,86 & 2441 \\
\hline Tanzania & 10,01 & 2316 \\
\hline Thailand & 29,33 & 14778 \\
\hline Timor-Leste & 37,17 & 2041 \\
\hline Togo & 12,13 & 1275 \\
\hline Trinidad and Tobago & 76,33 & 31926 \\
\hline Tunisia & 30,28 & 10579 \\
\hline Turkey & 35,12 & 21651 \\
\hline Turkmenistan & 57,09 & 13236 \\
\hline Uganda & 12,13 & 1637 \\
\hline Ukraine & 54,75 & 8339 \\
\hline United Arab Emirates & 58,7 & 62533 \\
\hline United Kingdom & 81,48 & 37130 \\
\hline United States of America & 115,13 & 51008 \\
\hline Uruguay & 82,29 & 19271 \\
\hline Uzbekistan & 35,55 & 5067 \\
\hline Vanuatu & 40,77 & 2890 \\
\hline Venezuela & 72,78 & 17665 \\
\hline Viet Nam & 55,22 & 5122 \\
\hline Yemen & 20,42 & 3873 \\
\hline Zambia & 13,04 & 3577 \\
\hline Zimbabwe & 18,24 & 1901 \\
\hline
\end{tabular}

\section{Sources: FAOSTAT (meat consumption); World Development Indicators (GDP)}

Note: 2013 numbers for both meat consumption and GDP. List includes all countries for which FAO provides meat statistics. Meat consumption based on FAO food supply statistics, meaning that numbers include meat wasted or otherwise not consumed by humans.

GDP per capita PPP (constant 2011 international dollars) 